Volume 30, 2020

http://journals.sfu.ca/cjsdw

\title{
Article
}

\section{Writing and Research Across the Globe: An Innovative North-North-South-South Collaboration}

Katie Bryant

Mangosuthu University of Technology and Carleton University

Codie F. LaLonde

Carleton University

Rachel Robinson

Michigan State University

Trixie G. Smith

Michigan State University

\section{Abstract}

This article is based on various versions of a panel presented at multiple writing centre and writing studies conferences as well as conversations across partners. Our perspectives come from discussions between our four universities before, during, and after an initial global North/global South writing support partnership meeting in the summer of 2018. During that summer, four universities (two in southern Africa and two in North America) partnered to begin a collaborative project of capacity building in the areas of writing centres and writing support across all levels of these universities, offering writing support to undergraduate and graduate students as well as earlycareer researchers/faculty. In this article, we share some of our ongoing concerns and considerations for ensuring this partnership moves forward in a collaborative, egalitarian, decolonial way that avoids both Western colonial and neo-colonial approaches to capacity building and program development. Reflections in this article can perhaps inform others working in the field of writing centre scholarship wanting to build similar global collaborations.

Keywords: Africa; decolonial; cross-cultural collaboration; wise practices; cultural rhetorics; rhetorical genre theory 
Volume 30, 2020

http://journals.sfu.ca/cjsdw

\section{Introduction: A N-N-S-S Collaboration}

In the summer of 2018, through the support of the Alliance for African Partnership (AAP) based at Michigan State University, four universities came together to develop a partnership around a collaborative project of capacity building in the areas of writing centres and writing support across all levels of these universities. Through this ongoing collaboration, we seek to offer writing support to undergraduate and graduate students as well as early-career researchers/faculty. Of the four partner universities involved in this initial project, two are based in the global South, and two are in the global North. Although this collaboration encompasses only four post-secondary institutions, we see this work as the beginning of a growing network of partners and exchanges globally. This potential for growth and expansion serves as the impetus for being careful and deliberate about the approaches we take to this first partnership. In this article, we share some of our ongoing concerns and considerations for ensuring this partnership moves forward in a collaborative, egalitarian, decolonial way that avoids Western colonial and neo-colonial approaches to capacity building and program development.

This article is based on various versions of a panel presented at multiple writing centre and writing studies conferences, as well as insights from all four partner universities discussing plans before, during, and after an initial global North/global South writing support partnership meeting in the summer of 2018. Katie introduces how our partnership began, providing scholastic context using Rhetorical Genre Theory (RGT) and the details of our North-North-South-South (N-N-S-S) partnership, including the demographics of the universities involved and the concept note that came from our initial meeting. Codie provides a benchmarking study she conducted as preparation for this collaboration and how the study helped her enter the collaboration 'with care.' Rachel uses a Cultural Rhetorics approach to story her position in the partnership and how she sees her value as a graduate student here moving forward. And Trixie elaborates on how a Cultural Rhetorics approach serves writing centres and collaborations. We conclude by sharing our evolving questions that are guiding us into the next steps with this partnership. Throughout, we also feature the voices and visions of our partners in the global South. 
Volume 30, 2020

http://journals.sfu.ca/cjsdw

\section{Katie: The Beginning}

In 2017, I returned to Carleton University to coordinate its university's writing centre after being out of this context for almost nine years. In my time away from working in writing centres in a North American context, I completed my Ph.D. in Writing Studies at McGill University, spending 2010 to 2014 exploring a group of academics' experiences and challenges writing for research purposes at the University of Botswana (UB)-located in Gaborone, Botswana-this southern African country's capital city. At UB, I taught writing and communication courses for university students. My study at this university sought to respond to the issue of African academics' low rates of publication in international academic journals ${ }^{1}$ compared to their North American and European counterparts (see figure 1).

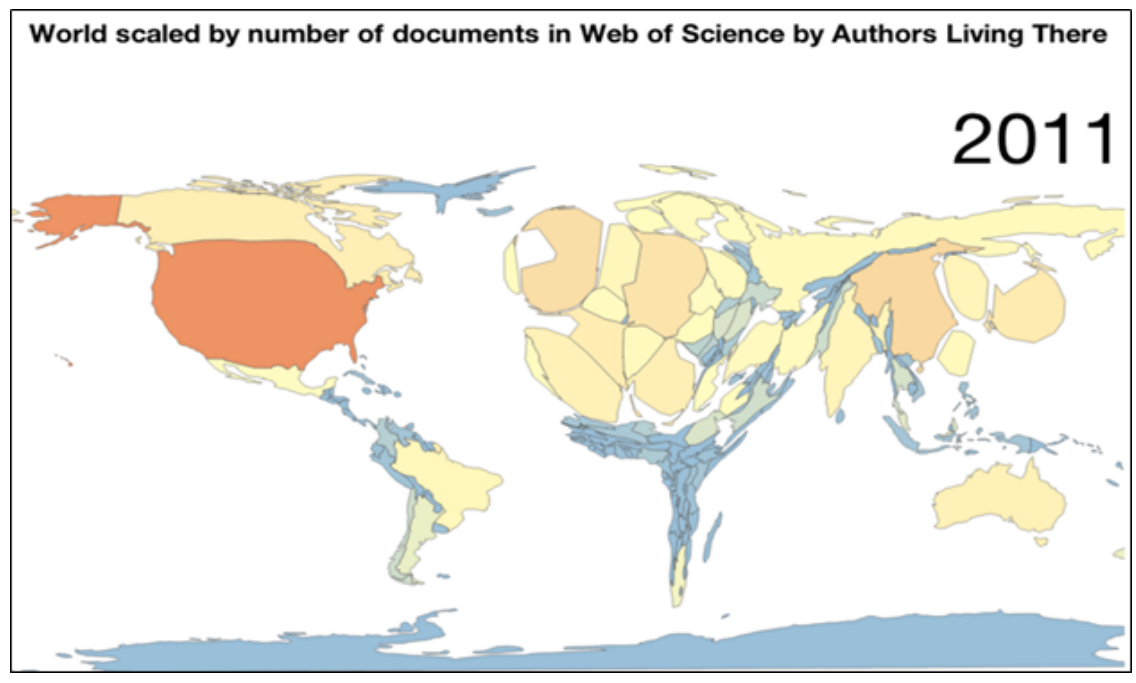

Figure 1. World Scaled by Number of Documents in Web of Science by Authors Living There, 2011

Note. Territorial size differences reflect the proportion of documents published in Web of Science-listed journals in 2011 by authors living there.

This issue has been well-documented by many researchers in both the global South (e.g. Mouton, 2010; Trotter et al., 2015) and global North (e.g. Lillis \& Curry, 2010). Likewise, the issue has been

\footnotetext{
${ }^{1}$ International academic journals are typically conceptualized as those indexed in two of the world's largest databases: Clarivate Analytics' Web of Science or Elsevier's Scopus. These journals are often sought-after because their accessibility gives them significant readership in their disciplines of study and often results in them being deemed the most "prestigious" in their scholarly communities.
} 
Volume 30, 2020

http://journals.sfu.ca/cjsdw

noted by higher education departments and granting councils in various African countries, such as South Africa's Department of Higher Education (DHET) (Department of Higher Education, 2020), as well as by international development institutions such as Canada's International Development Research Centre (IDRC), which has funded many researchers from the global South seeking to investigate and address this disparity (International Development Research Centre, n.d.). Although images like the maps above can be problematic, it is not intended to continue to disempower the African continent. Rather, many African scholars and researchers working on this issue use it to bring critical awareness of this disparity to the attention of those who may be unaware of these extreme rate differences-an awareness that published articles about this disparity do not make as apparent.

In addition to a significant amount of work by African researchers on this issue, the need and desire for African researchers to publish in international journals, which are often based in the global North, are also fraught with issues. Yet African academics, our southern African partners included, not only want but also often need to publish in journals located in the global North. This need stems from policies set by countries' ministries, such as South Africa's DHET, that offers monetary incentives to academics and higher education institutions in the country who publish in DHET accredited journals (Republic of South Africa, 2015).

Although research has been done on this issue, my investigations approached the issue from a slightly different angle, questioning how a lens of Rhetorical Genre Theory (RGT) could potentially shed further insights on these disparities. Not only had writing researchers' voices been absent from the conversation, but also African academics' voices about their experiences engaging in this activity had been absent. Thus, I questioned what further insights could be had about this issue by using a combined lens of Rhetorical Genre Theory with a methodology of decolonization to listen with intent to African scholars' experiences engaging in research.

From spending time working in the southern African region, I realized that few to no universities in this context seemed to draw on theories of writing studies or rhetorical genre studies research to make sense of their students' or their faculty members' challenges in writing for research purposes. Instead, students and faculty members were often blamed for their writing struggles, as writing was conceptualized as a skill, and their challenges were seen to only stem from these individuals being additional language users of English. Thus, throughout my time in this context, and as I returned home to Canada to embark on my research career, I questioned whether and how RGT could be used 
Volume 30, 2020

http://journals.sfu.ca/cjsdw

to better support both groups of writers with their writing work in this context. In returning to work in a Canadian university writing centre, I also wondered how a university writing centre could potentially function as a source of writing support on university campuses in southern Africa and what writing theories could inform this support. Yet, throughout asking these questions and engaging in work, my approach has been informed by listening with intent to our partners, the academics whose stories have been shared with me, and the students I have supported in learning how to write for their disciplines. And it is through listening with intent that I move forward in this partnership, particularly hearing about how the complex colonial or apartheid past of each individual's education system and higher education context more specifically has impacted their abilities to employ the rhetorical conventions of the various genres in which they are engaging. In the following section, I describe how the collaboration came to fruition and the entities involved.

This partnership began by building on long-term relationships starting in the early 2010s when I met Buyi Makhanya, who is now the Deputy Director of the Academic Literacy Language Unit (ALLU) at Mangosuthu University of Technology in Durban, South Africa. We first met at a teaching and learning conference in 2012 in South Africa, beginning a conversation after a conference presentation on South African students' challenges with writing for academic purposes. I suggested to the group how writing centre practices from the North American context could assist with these challenges. My comment led to the Deputy Director approaching me to inquire about how, because of my physical proximity to South Africa, I could assist their university in developing a university writing centresomething the Deputy Director was eager to begin at her institution. In 2013, I had the opportunity to visit this university in South Africa to get an initial understanding of the ALLU and the unit's vision for their future writing centre, and later that year, I returned to the university to conduct a three-day training for the lecturers and other staff members in the ALLU on writing tutoring practices.

The ease of this collaboration and support ceased because of physical proximity when I returned to Canada in 2014. During this time, though, many exciting developments took place in the ALLU that made the possibility of having a university writing centre feasible. The first was that space was acquired to house the centre, and basic equipment (such as tables, chairs, and computers) was purchased to furnish this space. In addition, funds were set aside to hire both a coordinator of the centre and writing consultants who would work with students daily, supporting them with their writing tasks. Despite the acquisition of equipment, which those of us who work in writing centres know is not always easy to acquire, the Deputy Director was still experiencing challenges in terms of 
Volume 30, 2020

http://journals.sfu.ca/cjsdw

beginning the daily business of the centre in a systematic way. In particular, they were experiencing challenges finding a centre coordinator, and neither she nor her two newly acquired ALLU lecturers had experience working in or coordinating a university writing centre.

Next entered the second important relationship that helped make this larger partnership a possibility: the former Deputy Director of the Office for Research and Development at the University of Botswana became a colleague and friend during my time working and living in this context. In 2016, she left this HEI to take up an interesting position at Michigan State University, which was seeking to build its partnerships with universities on the African continent. In one of our discussions, I mentioned the work I wanted to continue in my new role as coordinator of a Canadian university writing centre: exploring how university writing centres could be built and operated at universities on the African continent. I envisioned centres that drew not only on theories informed by additional language approaches to students' writing challenges but also on a rhetorical theory of genre. I also envisioned centres that functioned not only as a support for student writing but also acted as the epicentre for all writing support on the university campus, including offering faculty support in developing writing tasks and approaches to evidence-based writing pedagogy and helping them develop and strengthen their writing for research purposes. In our discussion, my former colleague thought of a funding opportunity her own organization at Michigan State University was offering to begin exploring the building of new partnerships between universities in the global South and those in the global North. Although the deadline was 15 days away, she introduced me to her institution's writing centre director to see if there was a way we could start this partnership. Luckily, this director, Trixie, was up for the challenge, and after a quick Skype call to introduce ourselves and discuss our ideas about the project, we began drafting a grant application via Google docs.

In the midst of these 15 days, my former colleague from South Africa also put us in touch with the Director for the Center for Research and Innovation at Botswana Open University (BOU) in Gaborone, Godson Gatsha, expanding our proposed project's focus from solely the writing centre context to building research capacities in Southern African universities. The addition of this final partner combined forces of four very different and interesting groups involved in supporting students and faculty members with writing at universities in the global North and global South. In the following section, I describe these different groups in further detail.

Carleton University is primarily a teaching university located in Ottawa, Canada. It opened in 1942 
Volume 30, 2020

http://journals.sfu.ca/cjsdw

to meet the academic and professional training needs of veterans returning from World War II. Currently, it has programs of study in more than 50 academic disciplines and approximately 31,000 students enrolled in courses of study with three-quarters of these students being in undergraduate programs. Michigan State University, in contrast, has a much longer history, opening in 1855 in Michigan as a prototype for the American land grant university, giving it, despite its researchintensive nature, a strong connection to its local, agricultural context. It has R1 status, meaning as an American university, it has the highest level of research-intensive activity according to the Carnegie Classification of Institutions of Higher Education. In contrast to its Northern partner, this university offers more than 200 programs of study for undergraduate, graduate, and professional students.

Alternately, Mangosuthu University of Technology (MUT) located in Durban, South Africa operates to promote research that seeks solutions to practical problems, particularly by developing innovative technologies, creating strong relationships between the communities in which it serves, engaging in technology transfer work, and giving specific focus to the scholarship of teaching and learning. Botswana Open University (BOU), our second Southern partner, became a university in 2017 with a focus on offering open and distance learning to post-secondary students in the country. BOU's strategic plans mandate developing support for graduate student and faculty research and writing, to include mentoring, training, facilitation of research dissemination through conferences and publications, and the establishment of both local and international partners to support this work in research and writing (Botswana Open University, 2018).

What came from this first week-long meeting is a collaborative concept note designed to help guide our path(s) forward: for planning purposes, for grant writing, and for sharing with other potential collaborators and supporters. This collaboratively written document was built on a communal set of problem statements that came from our daily discussions and strategic planning for the Writing and Research Across the Globe (WRAG) partnership:

1. Low rates of timely throughput and high rates of attrition across WRAG participating universities;

2. Need to increase the number and quality of doctoral degree holders on faculty at MUT and BOU; 
Volume 30, 2020

http://journals.sfu.ca/cjsdw

3. Need to address global research rate disparities between universities in the global North and South;

4. Limited experience in applying evidence-based theories of writing (praxis) at MUT and BOU; and

5. Limited opportunities for international writing partnerships to inform research and praxis in North American and southern African university writing centres.

Furthermore, according to this concept note, WRAG's stated purpose is "To enable university students and faculty members to develop their capacities in writing for academic and research purposes." Similarly, we agreed on a step one: “To implement a writing for research purposes support program for faculty members at MUT and BOU in order to increase the number of article submissions to the Department of Higher Education and Training [DHET] accredited journals." Two years later, we continue to communicate across distances and collaboratively refine these goals.

\section{Codie: Approaching Collaborations with Care}

In being aware of the narrative of the 'white enlightened saviour' (Cole, 2012; Bandyopadhyay, 2019; Guarino, 2018), I questioned and reflected upon how I could come into this N-N-S-S collaboration and project with care. That is, I did not want to engage in and/or reproduce that narrative. Of course, as a visibly-white woman living in a colonized nation and engaging in academia, saying one is aware of and resistant to colonial narratives is much easier than enacting a model of care in alignment with decolonizing approaches. Orienting oneself to and within decolonial approaches (Ahmed, 2012; Lorenz, 2018; Adams, 2014) is a perpetual learning and unlearning process, and I cannot claim to be an expert. However, based on personal reflection, discussions, and my general orientation to critical approaches to research and practice, I would suggest that if we (the global North) are to engage in capacity-building collaborations across multiple institutions, countries, and contexts (especially in North-South/South-North partnerships), we must do so in a way that does not overbear, overshadow, or condescend.

In preparing for our trip to Botswana, with Katie's guidance, I carried out a small benchmarking study that aimed to help all parties get a sense of what already exists, where we might start, and where we might go. In conducting this study, I collected data about writing centres (WCs) in public 
Volume 30, 2020

http://journals.sfu.ca/cjsdw

universities in South Africa and Botswana, using my disciplinary background in Critical Discourse Studies (Wodak \& Meyer, 2016; Fairclough, 1995) and Corpus Linguistics (Mautner, 2016) to analyze how WCs or writing supports are characterized (discursively constructed) across these universities. For this study, South Africa is used as the reference point, given that only its universities had writing centres. This research was both a stepping-stone for me, as it gave me some historical and contextual knowledge of the countries' universities, and for the collaboration as a whole.

\section{Critical Pedagogy \& Critical Discourse Studies (CDS)}

My research and practise are oriented within a critical perspective, and through this, I've taken up both Critical Pedagogy and Critical Discourse Studies (CDS) as theoretical understandings and methodological approaches. For me, Critical Pedagogy as informed through Paulo Freire's lifework (mainly Pedagogy of the Oppressed and Pedagogy of Hope; see also Giroux, 2011) weaves together threads such as honouring prior knowledge and experiences (see also Scorza, Mirra, and Morrell, 2013), meeting folks where they are, awareness of the intersections, listening and hearing, critical reflection, and calls for and action toward social justice (speaking truth to power). Of course, the term pedagogy refers to theories of teaching and learning; however, these threads very much align with my approach to everyday life, and I see university writing centres as significant educational hubs that ought to be pedagogically and research informed. CDS facilitates a diverse and social justice-oriented approach to analysis as it questions "common-sense assumptions" (Fairclough, 1989) through critical attention to the relationships between language/discourse, ideology, and power (see Wodak \& Meyer, 2016 for a good introduction). Important aspects and processes of CDS include critical interpretation of and reflection on a text's (written, verbal, multimodal, etc.) parts and strategies through the use of various 'tools' (micro analysis), as well as attention to both the immediate and broader social context in which the text is situated (historical, political, cultural, economic, etc.)that is, produced and consumed (meso and macro analysis).

\section{Benchmarking Study}

Public universities in South Africa fall into three categories: traditional, comprehensive, and universities of technology (née teknicons) (Bunting \& Cloete, 2010). I visited each university's website and looked for evidence of a Writing Centre (WC) at each institution using the menu and search functions and documented what I found (or didn't find) in a spreadsheet. This included how it was referred to (e.g., Writing Centre, Writing Lab, etc.), where it was housed within the university 
Volume 30, 2020

http://journals.sfu.ca/cjsdw

(e.g., teaching and learning unit, student academic support centre, etc.), and any relevant details (what kinds of students it serves, whether the page requires log-in information or has supporting information). For those pages that had supporting information (a blurb about the Writing Centre's function, roles, hours, etc.), I copied and pasted the descriptive information into a Word document for additional analysis.

In preparation for our trip, I visualized the data for a more engaging presentation and discussion. The figures below show the data from South Africa. ${ }^{2}$ Figure 2 shows both the breakdown of traditional, comprehensive, and technical universities $(12,6$, and 8 respectively), as well as whether or not a WC webpage could be found through the university website.

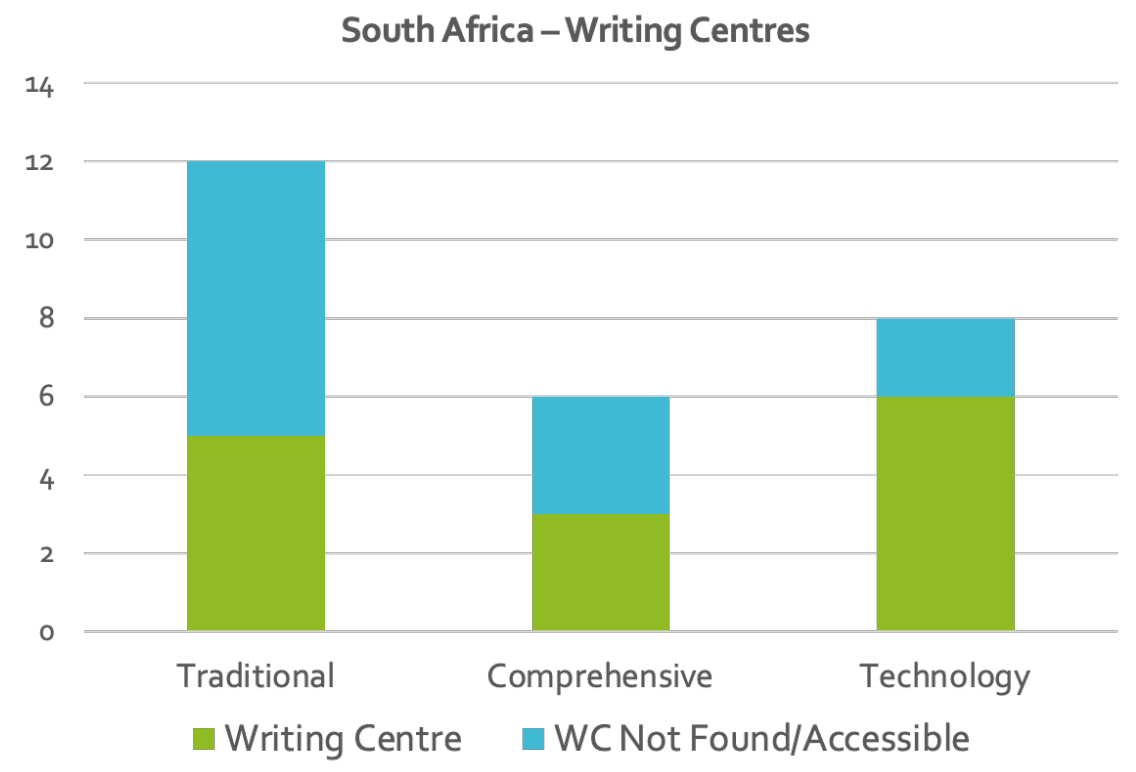

Figure 2. South African Universities' Writing Centres

Interestingly, universities of technology were most likely to have accessible WC webpages, while many traditional universities either did not have accessible WC information or did not have WCs. While some universities did not have a WC webpage (at the time of this research), I was able to find some evidence via browsing and search functions that they may have some type of writing support through, for example, job advertisements for writing consultants or coordinator positions, or news

\footnotetext{
2 I was not able to find accessible evidence of writing centres in Universities in Botswana at the time of data collection.
} 
Volume 30, 2020

http://journals.sfu.ca/cjsdw

articles mentioning a writing centre. Thus, it must be stressed that lack of web-based evidence of a WC does not mean writing supports or centres (be they official or unofficial) do not exist in some capacity.

As Lunsford and Ede (2011) point out, where WCs are housed "carries both material and symbolic location" (as cited in Monty, 2017, p. 8). We focused on this mainly because we (all collaborators) would have to be mindful of 'the politics of location' (Monty, 2017) in capacity-building as we hoped to aid in the development of writing support and the eventual set up of Writing Centres at MUT and BOU. Figure 3 shows where WCs in South African Universities are housed.

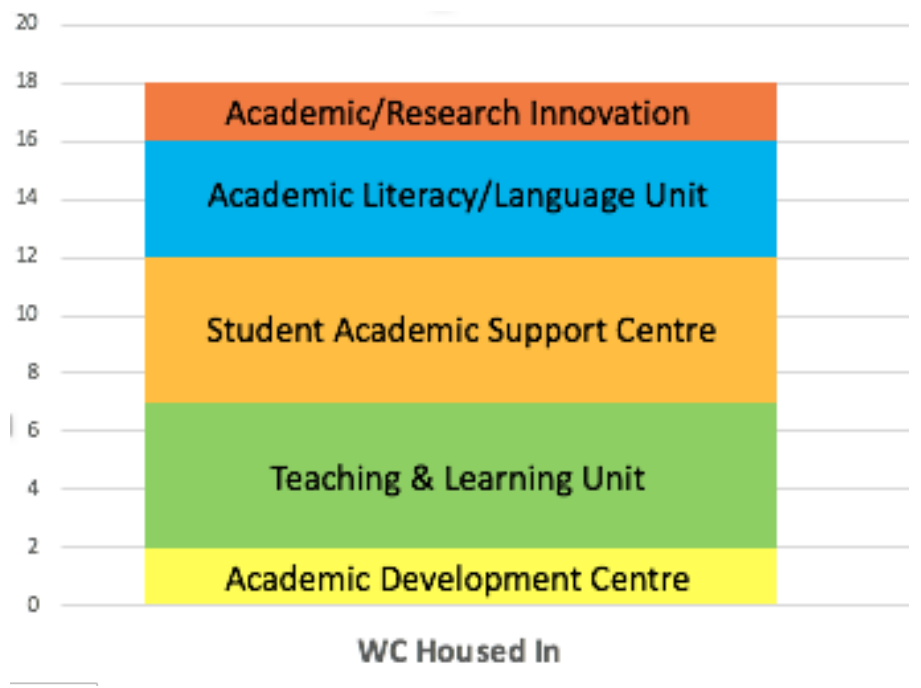

Figure 3. Where South African University Writing Centres are Housed

Here, we can see the breadth of where WCs are housed, as well as commonalities across where WCs are housed in South African and North American contexts. Across all universities, WCs were most likely to be housed in a student academic support unit or a teaching and learning unit. However, some of the academic literacy and/or language units are housed within teaching and learning centres, while some universities have discipline-specific WCs such as for humanities students and journalism students. One university appears to have a stand-alone WC. Further research might gather a fuller picture of these units by mapping the universities' organizational structure and possibly noting and exploring similarities and differences across each type of university (e.g., traditional, comprehensive, or technological).

In the second phase of this benchmarking study, I used AntConc software to generate a list of 
Volume 30, 2020

http://journals.sfu.ca/cjsdw

frequent word clusters (Table 1), which shows some characteristics of these WC blurbs.

Table 1. Writing Centre Web Page Word Clusters

\begin{tabular}{ll}
\hline Freq. & Word Cluster \\
20 & writing centre(s) \\
12 & academic writing \\
7 & writing skills \\
6 & one-on-one \\
4 & help students \\
4 & not edit \\
3 & academic writing skills \\
3 & assist students \\
2 & academic literacies \\
2 & academic performance \\
\hline
\end{tabular}

Clusters such as 'writing skills,' 'not edit,' 'assist students,' and 'help students' are what we might expect in a WC blurb in most contexts, and this rings true in the South African context. In viewing each of the WC web pages and their content, I shared some general observations with our collaborators: in the information provided on South African WC webpages writing is viewed as a process; writing is seen as a skill that can be developed and honed; writing is tied to academic performance, and writing centres aim to enhance this performance; and WCs are typically positioned as a support service regardless of location. While these underlying assumptions are fairly common in the knowledge-based economy (where knowledge and skills are viewed as capital), pointing them out provides the opportunity to grapple with them.

When it came time to think about what recommendations I would make as a result of the benchmarking study, I thought back to the literature on writing centres and some of the struggles that they have (Pare, 2017; Monty, 2016; Okuda, 2017; Klostermann, 2017); some of the recommendations writing scholars make; and my experiences as a writing consultant in my own institution. From there, I came up with three general areas that could be considered for our collaborations. Rather than engaging with the colonial notion of 'best practices,' ${ }^{3}$ I hoped to just

\footnotetext{
3 In my view, 'best practices' are often a colonizing and one-size-fits-all endeavour which leave little room to consider aspects such as context and culture (see Crampton, 2015; Steiner-Khamsi, 2012).
} 
Volume 30, 2020

http://journals.sfu.ca/cjsdw

highlight good or conscientious practices (as they exist in a North American context and in some of the collected WC blurbs), as well as areas where development would be relatively easy to implement. In my view, more substantive observations and recommendations need to be developed through discussion with all parties (co-produced), rather than an arms-length (or ocean's length) 'looking in.' Based on these reflections, some emerging discussion points for consideration were that writing centres (or affiliated support) should have 1) easily accessible/advertised information via the university website amongst other avenues; 2) clarity about the roles that the consultants/tutors perform (e.g., not an editing service); and 3) clarity about the role of the attendee (students, staff/faculty), such as to come with an open mind and willingness to take initiative, bring assignment/writing guidelines and draft(s), etc. Presenting this preliminary benchmarking study to our collaborators acted as a jumping-off point for the activities and discussions that took place during our week together, which Trixie details in this paper.

\section{Rachel: A Cultural Rhetorics Story}

As we prepared to revise our panel presentation for the 2019 Canadian Association for the Studies of Discourse in Writing (CASDW) conference, I found myself coming back again and again to the conference theme of "Circles of Conversation" and asking myself how this theme might apply to our $\mathrm{N}-\mathrm{N}-\mathrm{S}-\mathrm{S}$ partnership. What I realized is that more than any other conference theme, the idea of circles provided an apt metaphor for me to see this partnership clearly.

I see my work in writing centres, and with this project, as more than a typical set of concentric circles. From what I understand, concentric circles all share a common centre, rippling out from there to encompass bigger and bigger space; yet their lines do not ever intersect. It's easy to see how WCs, writing studies, and even academic collaborative partnerships would easily fit into this model with a shared centre, a common goal; however, I see my WC work more as a circular geometric pattern, like a mandala, where the lines overlap and create new paths along with the existing ones, where the centre is relative to one's orientation to certain lines, and where the space is intersected, opening up to encompass all the work, knowledge, and experience of multiple communities at once.

I want to tell you a story, and, in doing so, I want to broaden my circle out to meet yours, inviting you to find intersections and paths to cross where you see fit.

Lately, I've found myself thinking about a tutoring session I had with an undergraduate writer 
Volume 30, 2020

http://journals.sfu.ca/cjsdw

early in my writing centre career. The writer's name is Eddie ${ }^{4}$, and he and I only had one session. We met during my third year working in writing centres, my second as a graduate consultant during my MA, on an inauspicious day toward the end of the spring semester. At this point, this memory is sixteen years old, so it's a bit foggy, but the important details are still clear. The centre was busy, as you can imagine, and when Eddie came in, I remember ushering him to one of the quieter tables facing a wall in our cramped centre. Immediately when we sat down, I launched into the WC spiel:

How're you doing? How about this weather? Have you been here before? Do you have an assignment sheet? What can I help you with?

I breezed through all of these questions without really looking at Eddie or registering what his answers were. Everything that had to do with a session, especially at this time of year, had become routine for me, and the stress of the writers who were coming to see us-and my own student stress-made me feel like I needed to operate with a quick clip.

Eddie sat still beside me and patiently answered my questions. He had an assignment sheet, and as I skimmed it, he pulled up his essay on his laptop. When it was time to focus on the essay itself, I began reading it aloud. I don't even remember if I asked him if it was okay. All these years later, I have trouble remembering the bulk of what his essay was about, or even what he came in wanting help with. What I do remember is that Eddie was an Aerospace major, and his paper was about taking his first solo flight as a pilot. I also remember that as I kept reading his paper, his lyrical writing struck me and forced me to slow down and really listen to his words that I read aloud because I didn't want to miss any of them.

This essay was good. I mean really good. Sure, it had a few grammatical issues, but this was a writer who knew how to grab his audience. He wrote about taking the controls of the plane with confidence for the first time, how the power of the plane felt as it trundled down the runway, and what it felt like to be all alone with his life, quite literally, in his own hands. As we came to the last page, I'll never forget that he had a line describing the plane's ascent in which he said that the sky was a "ribbon of blue unfurling in front of [him]." When I got done reading, I was surprised to see that I actually had tears streaming down my face. I hadn't even realized I was crying during the session, but I was so

\footnotetext{
4 This is a pseudonym.
} 
Volume 30, 2020

http://journals.sfu.ca/cjsdw

moved by his writing, by the stillness of it, by the quiet power that his words commanded, that I couldn't help myself.

To his credit, Eddie was unmoved by my spectacle and just watched me as I quickly wiped my eyes, complimented his work, and asked if he needed any more help. He said no and quickly left the centre. I have no idea how he interpreted my tears, and I never saw him again. I don't mean for Eddie to be a stand-in for all writers in the centre; rather, I tell our story to show what I could have missed in our session had I not slowed down and listened to my writer and his words.

When I found out I'd be joining the N-N-S-S project and working with our Canadian and southern African partners, I was both thrilled and nervous, and I was reminded of my session with Eddie so long ago. While I've worked in writing centers since 2002 in various capacities, this project came about at an incredibly inopportune time for me academically and personally, and I struggled with what I might add to it as a graduate student. As you might know, if you are a graduate student or from the graduate students in your life, our schedules are tight with deadlines and lousy with personal life, and if we want to complete degrees, apply for fellowships, do research, and collect data, everything needs to move ON TIME. Therefore, like many academics, graduate students are busy, sometimes rightfully so, sometimes not, but nevertheless, our time is filled. My time was filled when this project came along: I had just completed coursework and was in the middle of my concentration exam, yet, ironically enough, I was also looking for projects I could keep cramming into my schedule.

Personally, my life was in a bit of a shambles. My mother passed away in January of 2018, and I was doing everything I could academically to keep myself from stopping long enough to sit with my grief. When I was invited to join this research, on the one hand, I thought-YES! Something else I can pile onto my day, so I don't have to stop and THINK! And on the other hand, I thought—NO!! You're already barely hanging on!!

However, when the invitation came, I barely took a beat before accepting and mentally starting to pack my bag. Walking out of Trixie's office, I was Googling Botswana on my phone, and by the time I reached my car, I'd already made a Pinterest board of travel tips.

I felt like this partnership was exactly the kind of work my WC life and scholarship needed. When I returned to school for my Ph.D., I'd been professionally working in WCs as an administrator for over 
Volume 30, 2020

http://journals.sfu.ca/cjsdw

a decade. I missed the bustle of tutoring, something my administrative jobs didn't allow me time for, but once I jumped back into tutoring, my work quickly felt stale. I couldn't reconcile my day-to-day tutoring troubles and exhaustion with my admin knowledge, and I wasn't able to be an admin anymore. I had a lot of practice telling myself to stay in my own lane that first year, but my own lane was lacking scenery and excitement. I needed to get back into WC research in a way that made me feel like I was contributing, but I also didn't know how-or what-to contribute anymore.

To complicate matters even further, this collaboration was only tangentially related to my main research areas. Mentally, I was having a difficult time figuring out how I fit into the collaboration and how the collaboration fit into my own work, but I wasn't ready to give it up. All of my work felt like it had a common centre-writing centres-but it mostly stood fairly independently, an intentional choice I made when returning to school. Once I realized this-and I mean I actually sat down and mapped it out-something clicked. I remembered my session with Eddie.

Recalling my session with Eddie has had a profound impact on my academic life, and on how I approach this partnership. That session continues to be a touchstone for my WC work in many ways, but none more profoundly than in the pull it has had on me to slow down. I'm used to working for results-I always work with deadlines in mind and breaking a project down to its bare essentials in order to create an efficient working process is one of my favorite academic past-times. But I've recently been trying to understand how my own work tendencies can work best alongside those of my grounding theoretical frameworks and my new desire to slow down, so I don't miss the ribbon of sky.

I consider myself a budding cultural rhetorician, a study and practice of meaning-making that centers on the idea that all cultures are rhetorical and all rhetorics are cultural. Additionally, Cultural Rhetorics (CR) work is supported by four tenets: decolonization, relationality, constellation, and story (Bratta \& Powell, 2016). Likewise, much WC theory revolves around celebrating and valuing writers' stories and helping them bring those stories to their compositions (e.g. Lunsford, 1991; Cooper, 1994; DiPardo, 1992; Woolbright, 1992; Grutsch McKinney, 2013, to name a few). As I prepared for our N-N-S-S partnership and what my role could be in it, these tenets kept ringing in my ears, especially as I considered my own positionality within this partnership: white, female, Ph.D. student. What could I offer this partnership that would not further perpetuate a Western stance of colonization? How could I come to this group prepared to offer my own expertise from the field of 
Volume 30, 2020

http://journals.sfu.ca/cjsdw

writing centres and writing instruction while still understanding the limitations of my positionality within the hosting cultures and universities? What did coming to this project with care look like for me? Thomas King (2004) reminds us that "it is hard to break free from the parochial and paradoxical considerations of identity and authenticity" (p. 44), yet when working with partners to build programmatic frameworks, these longstanding, colonial considerations of identity are too-often deemed 'right,' even when they might actually be harmful. How do we resist the harm-actively push against it-while still honouring the cultures of the communities in which we work?

As practitioners in WCs, writing studies, and writing program administration, we must remember that our programs are not one-size-fits-all. Our differences should affect our programs, and our programs should be flexible enough to work with (and within) our different identities to create and celebrate the stories within us all. This means we need to let our egos go. We should slow down and listen to our stories and realize that lasting partnerships take time, and creating new paths in which our own lives and work can intersect with others in difficult, but not impossible, work. As King tells us, "The truth about stories is that that's all we are" (2004, p. 32). And lasting partnerships begin with authentically sharing stories.

So, someone looking on from the outside might think that my approach to this partnership was one of passive traveller, a graduate student just along for the ride. Indeed, not a lot of physical action - the building of the centres or programs—has taken place, particularly on my end.

Instead, I've changed what research looks like for myself. I've slowed down. I've listened. I've sat with my new southern African and Canadian partners and shared tea and stories and laughs and Facebook messages, and birthday love, and picture likes, and congratulations, and condolences, and the circles I stand in have shifted again, constellating a new pattern.

\section{Trixie: Cultural Rhetorics in the Writing Center}

Since I first received emails from the AAP and Katie inviting me to consider this collaboration, I have worked to see both the big picture-possibilities for numerous partnerships and collaborationsand the small, local picture we would use to begin this journey, or these concentric circles if you will. Having supported multiple folks in the building of writing centres in different contexts, I knew it was important to start with small, manageable goals even while working towards big dreams and networks of possibilities. 
Volume 30, 2020

http://journals.sfu.ca/cjsdw

As we slowly build this work, we envision it as the beginning of what will be a growing network of partners and exchanges expanding from both origin points in the global South and the global North. As mentioned previously, this potential for growth and expansion necessitates an approach to partnerships that is both careful and deliberate. We're committed to moving forward in a collaborative, egalitarian, decolonial way that avoids both Western colonial and neo-colonial approaches to capacity building and program development. We're also committed to enacting new paradigms that build through intersectional practice, combining good practices and lessons from cultural rhetorics, rhetorical genre theory, critical pedagogy, and other such methodologies that help us support and interrogate this work simultaneously. But putting theory into action isn't always easy.

According to Linda Tuhiwai Smith (1999), in Decolonizing Methodologies: Research and Indigenous Peoples, Western research "brings to bear, on any study of indigenous peoples, a cultural orientation, a set of values, a different conceptualization of such things as time, space, and subjectivity, different and competing theories of knowledge, highly specialized forms of language, and structures of power" (p. 42). We wished to avoid this approach to research, capacity building, and collaboration when developing our North-North-South-South partnership.

We did not want to study our partners in southern Africa; we wanted to study the work of establishing writing centres and writing support in this new context with our partners. We were interested in learning what they wanted and needed. During the planning stages, both MUT and BOU voiced a desire to build capacity across their changing programs with new emphases on research and publication. As Godson and his colleague Changu Batisani put it, BOU wanted to recruit and retain high-quality students and faculty and to establish a good public image. Godson said in our workshop that it was "through writing that academic excellency could be attained." For MUT, Buyi and her colleague Hloniphani Ndebele, also part of the week-long collaboration, expressed an urgency for conducting a writing and research needs analysis with both students and faculty (work that has begun). Their plans for a writing centre were much more established as Katie described earlier, but they wanted to set it up for success from the beginning, including buy-in from all of the various stakeholders. Consequently, when we came together, the first exercise we did across all four partners was a Goals and Dreams exercise designed to get everyone to think big, be creative, and even be idealistic. Our Southern partners described their visions for writing centres, tutor training, faculty development as teachers of writing, and research writing support. We, as the northern partners, did the same, dreaming about what we wanted from the partnership or what we could build that would 
Volume 30, 2020

http://journals.sfu.ca/cjsdw

benefit our students and our universities. We visualized faculty and graduate student exchanges, study abroad possibilities, collaborative research and publication. We wanted each and every person at the table to share their stories and possibilities. We envisioned this exercise as one way of distributing power and sharing expertise.

At times, however, we found our desire to be decolonial in our approaches disrupted by our Southern partners' positioning of us as the experts on writing, writing support, and writing centersthe things they were seeking. We didn't want to downplay our knowledge and what we had to offer, but we also wanted to acknowledge that much of this positioning was due to years of colonization and Western (British, more specifically) approaches to the teaching of writing. Consequently, we sought ways to gently and subtly resist the positions into which we'd been placed, while also quietly empowering our partners. In doing this, we worked not to claim a position of "innate superiority" or a desire to "bring progress," as Tuhiwai Smith has said (1999, p. 56).

This approach to partnerships also stems from my cultural rhetorics approach to WCs, which, for me, is rooted in intersectional theories and approaches, including queer, feminist, and indigenous methodologies. The CR lens that Rachel explained earlier in this paper helps me envision my pedagogies and philosophies in the WC. For example, I build WCs on a shared expertise model, or a complementary expertise model, as one of my mentors used to say. Both tutor and writer bring expertise to a session, just as both sets of partners were bringing expertise to this collaboration. WCs also work from a strengths model, not a deficit model, as Katie and Codie both mentioned. It is much more productive to build from what is working than to focus on what is missing or not working.

Likewise, part of what I teach my writing consultants is how to be culturally aware and sensitive to various aspects of writing and existing in the academy. In training, we discuss how different disciplines, schools, cultures, individuals have different expectations for and experiences of writing and conducting research. There is also a wide range of expectations centred around how one runs a class or performs in the university. I invite consultants to examine the different leadership styles and learning styles writing tutors encounter as they work with others, both colleagues and clients. We talk about the WC as a place for community building and sharing across both similarities and differences. A CR approach to WCs allows space for relationality, reciprocity, and storytelling. I extend these lessons from one-on-one sessions, to writing groups, to workshops, to global partnerships. 
Volume 30, 2020

http://journals.sfu.ca/cjsdw

\section{Conclusion: Evolving Through Ongoing Questions}

As mentioned previously, even as discussions and plans continue and slowly evolve, we're left with a lot of questions; this is very much a work-in-progress, and our concentric circles are definitely still rippling. We leave you, the reader, with some of these questions, and important insights from one of the Southern collaborators, Ndebele, that both we, as the Northern partners, and you as the reader, might want to consider if wanting to engage in this type of partnering in the future: First, as the Northern partners, we question how we can work with our Southern partners to design mutually beneficial opportunities for all of us as collaborators to not only use but also showcase each partner's expertise. It's important that we each know what the others need and what they know about their/our own institutions to create viable programs for each partner's schools and students. As we work with our Southern African partners, for example, we ask how we can offer our own expertise from the field of writing centres and writing instruction while still understanding the limitations of our positions within the hosting cultures and universities. Sometimes it's hard to know what you don't know, but it's something we have to pay attention to, something we want to pay attention to.

Within such questioning, and particularly in the attempt to work within a framework of decolonization, it is important to understand the complex policy and historical context in which one's Southern partners are situated. For instance, as Hloniphani, our colleague at MUT explained to us in recent conversations, the decolonization landscape in South Africa is complex, particularly in higher education and in regards to efforts to decolonize its curriculum (Council on Higher Education, 2017). To successfully engage in decolonization work, all members of our partnership need to become wellversed in each country's complex context to understand its complexity fully. For example, it's important to understand where the Southern partners are situated in this work, for what reasons, and how they want to enact decolonization work in their respective locations.

Second, and within these above questions, we, as the Northern partners, need to ask how we adapt our Northern (Western) WC models to these new contexts. For example, we can't reproduce exact duplicates of our Northern writing centres in our Southern partners' locations. So how do we work together to envision a viable model that is still rooted in good practices and operating under theoretical lenses that work for all of us, particularly in light of complications such as numerous online courses and limited Wi-Fi access outside the city? How do we build centres around nonexistent or newly established writing courses? 
Volume 30, 2020

http://journals.sfu.ca/cjsdw

As we seek answers to these big, broad questions, we go back to our theorizing and ask: Can Rhetorical Genre Theory and Cultural Rhetorics be combined and critically (re)oriented to reframe conceptualizations, to design new ways to address writers' challenges in the global South? Can they offer an innovative and 'empowering' lens? Can methodological and theoretical pluralism lead us to something new and innovative that will be successful in these new contexts? How do we do wise work with intersecting theories?

As you can tell, we have more questions than answers at this point, but we think the questions are an important place to start. We see the questions as initial stones in the pond that start the ripples of that inner circle in Rachel's story.

\section{References}

Adams, G. (2014). Decolonizing methods: African studies and qualitative research. Journal of Social and Personal Relationships, 31(4), 467-474. doi:10.1177/0265407514521765

Ahmed, S. (2012). On being included: Racism and diversity in institutional life. Durham, NC: Duke University Press.

Bandyopadhyay, R. (2019). Volunteer tourism and "The White Man's Burden": Globalization of suffering, white savior complex, religion and modernity. Journal of Sustainable Tourism, 27(3), 327-343. doi:10.1080/09669582.2019.1578361

Botswana Open University (2018). Notes on a comprehensive approach to promoting a culture of research at the Botswana Open University.

Bratta, P. \& Powell, M. (2016). Introduction to the special issue: Entering the cultural rhetorics conversation. Enculturation, 21. Retrieved from http://enculturation.net/entering-the-culturalrhetorics-conversations

Bruffee, K. (1984). Collaborative learning and the "conversation of mankind." College English, 46, 635-652.

Bunting, I., \& Cloete, N. (2010). Institutional types in higher education in South Africa. Centre for Higher Education Transformation. https://open.africa/organization/centre-for-highereducation-transformation

Cole, T. (2012, March 21). The white-saviour industrial complex. The Atlantic. Retrieved from https://www.theatlantic.com/international/archive/2012/03/the-white-savior-industrialcomplex/254843/ 
Volume 30, 2020

http://journals.sfu.ca/cjsdw

Cooper, M. (1994). Really useful knowledge: A cultural studies agenda for writing centers. In C. Murphy \& J. Law (Eds.), Landmark essays on writing centers (pp. 135-150). Davis, CA:

Hermagoras.

Council on Higher Education. (2017). Decolonising the curriculum: Stimulating debate: Number 3. Pretoria, South Africa: Council on Higher Education.

Denny, H. (2008). Writing centers and politics of community, identity, and social justice. In K. Dvorak and S. Bruce (Eds), Creative approaches to Writing Center work. (pp. 49-69). Cresskill, NJ: Hampton Press.

Department of Higher Education. (2020). Ministerial Statement on the implementation of the University Capacity Development Program 2021-2023.

DiPardo, A. (1992). "Whispers of coming and going”: Lessons from Fannie. In C. Murphy \& J. Law (Eds.), Landmark essays on writing centers (pp. 211-226). Davis, CA: Hermagoras.

Fairclough, N. (1989). Language and power. New York, NY: Longman.

Fairclough, N. (1995). Critical discourse analysis: The critical study of language. London, UK: Longman.

Fox, H. (1994). Listening to the world: Cultural issues in academic writing. Urbana, IL: NCTE.

Freire, P. (1998). Pedagogy of hope: Reliving pedagogy of the oppressed. London, UK: Bloomsbury Academic.

Freire, P. (1996). Pedagogy of the oppressed. London, UK: Penguin.

Giroux, H. A. (2011). On critical pedagogy. London, UK: Continuum.

Giroux, H. A. (2016). Beyond pedagogies of repression. Monthly Review, 67(10), 57-71.

Grutsch McKinney, J. (2013). Peripheral visions for writing centers. Boulder, CO: UP of Colorado.

Guarino, J. (2018, September 11). Holding up the mirror: Recognizing and dismantling the "White Savior Complex." Medium. Retrieved from https://medium.com/mama-hope/holding-up-themirror-recognizing-and-dismantling-the-white-savior-complex-61c04bfd6f38

International Development Research Centre. (n.d.). Scholarly Communication in Africa Program. https://www.idrc.ca/en/project/scholarly-communication-africa-program

King, T. (2003). The truth about stories: A native narrative. Toronto, ON: House of Anansi Press.

Klostermann, J. (2017). Writing on the ground. CJSDW/R, 27, 19-23.

Lillis, T., \& Curry, M. J. (2010). Academic writing in a global context: The politics and practices of publishing in English. London, UK: Routledge. 
Volume 30, 2020

http://journals.sfu.ca/cjsdw

Lorenz, D. E. (2018). Pedagogies of resistance: Living resistance by writing. Canadian Journal for New Scholars in Education, 9(1), 6-14.

Lunsford, A. (1991). Collaboration, control, and the idea of a writing center. In C. Murphy \& J. Law (Eds.), Landmark essays on writing centers (pp. 109-116). Davis, CA: Hermagoras.

Mautner, G. (2016). Checks and balances: How corpus linguistics can contribute to CDA. In R. Wodak \& M. Meyer (Eds.), Methods of critical discourse studies (3 ${ }^{\text {rd }}$ ed.) (pp. 154-179). London, UK: Sage.

McNaught, C., \& Lam, P. (2010). Using Wordle as a supplementary research tool. Qualitative Report, 15(3), 630-643.

Mouton, J. (2010). The state of social science in sub-Saharan Africa: knowledge divides (background paper). Paris: International Social Science Council. Retrieved from http://unesdoc.unesco.org/images/0019/001906/190659E.pdf

Okuda, T. (2017). What a generalist tutor can do: A short lesson from a tutoring session. Canadian Journal for Studies in Discourse and Writing/Rédactologie, 27, 58-68. doi: 10.31468/cjsdwr.580 Paré, A. (2017). The once and future writing centre: A reflection and critique. Canadian Journal for Studies in Discourse and Writing/Rédactologie, 27, 1-8. doi:10.31468/cjsdwr.573

Republic of South Africa. (2015). Research outputs policy (Government Gazette No 38552). Pretoria, South Africa: Government Printing Works.

Smith, L. T. (1999). Decolonizing methodologies: Research and Indigenous peoples. London, UK: Zed.

Trotter, H., Kell, C., Willmers, M., Gray, E., Totolo, A., \& King, T. (2014, March). Scholarly communication at the University of Botswana case study report. Retrieved from http://open.uct.ac.za/bitstream/handle/11427/2356/SCAP_Trotter_CaseStudyUniversityBotsw ana_2014.pdf?sequence=1

Wilson, S. (2008). Research is ceremony: Indigenous research methods. Halifax, NS: Fernwood Wodak, R., \& Meyer, M. (2016). Methods of critical discourse analysis. London, UK: Sage.

Woolbright, M. (1992). The politics of tutoring: Feminism within the patriarchy. In C. Murphy \& J. Law (Eds.), Landmark essays on writing centers (pp. 227-240). Davis, CA: Hermagoras. 